\title{
Establishment and characterization of triple drug resistant head and neck squamous cell carcinoma cell lines
}

\author{
SINDHU VALIYAVEEDAN GOVINDAN ${ }^{1,2}$, SAFEENA KULSUM $^{1,2}$, \\ RAMANAN SOMASUNDARA PANDIAN ${ }^{3}$, DEBASHISH DAS ${ }^{3,4}$, MUKUND SESHADRI $^{5-7}$, \\ WESLEY HICKS JR ${ }^{6,7}$, MONI ABRAHAM KURIAKOSE ${ }^{1,2,7}$ and AMRITHA SURESH ${ }^{1,2,7}$
}

\begin{abstract}
${ }^{1}$ Integrated Head and Neck Oncology Research Program, DSRG-5, Mazumdar Shaw Centre for Translational Research, Mazumdar Shaw Medical Foundation, Narayana Health; ${ }^{2} \mathrm{Head}$ and Neck Oncology, Mazumdar Shaw Medical Centre, Narayana Health; ${ }^{3}$ GROW Laboratory; ${ }^{4}$ Stem Cell Research Lab, Narayana Nethralaya, Narayana Health, Bangalore, Karnataka 560099, India; Departments of ${ }^{5}$ Pharmacology and Therapeutics, and ${ }^{6} \mathrm{Head}$ and Neck/Plastic and Reconstructive Surgery, Roswell Park Cancer Institute; ${ }^{7}$ Mazumdar Shaw Medical Centre-Roswell Park Collaboration Program, Roswell Park Cancer Institute, Buffalo NY 14263, USA
\end{abstract}

Received March 22, 2014; Accepted March 3, 2015

DOI: $10.3892 / \mathrm{mmr} .2015 .3768$

\begin{abstract}
Resistance to chemotherapy leading to poor outcome and survival remains a challenge for developing strategies for therapeutic interventions in all types of cancer, including head and neck cancer. In vitro chemoresistant cell line models are an indispensable resource towards delineating the mechanisms involved in drug resistance/response and for the development of novel drugs. Current treatment for head and neck cancer includes chemotherapy with cisplatin, docetaxel and 5-fluorouracil (5-FU) and the response rates to these drugs in patients is $60-80 \%$. The present study aimed to generate head and neck cancer triple drug-resistant cell lines in an effort towards elucidating the mechanisms underlying chemoresistance and providing a resourceful tool for drug design. Using two head and neck squamous cell carcinoma cell lines, Hep-2 (larynx) and CAL-27 (oral cavity), the present study sequentially exposed these cells to increasing concentrations of the combination of docetaxel, cisplatin and 5-FU (TPF) to generate triple drug-resistant cells, termed Hep-2 TPF resistant (TPFR) and CAL-27 TPFR. The effect of the drug treatments on the cell viability, apoptosis, cell cycle and the expression of genes associated with multidrug resistance were analyzed in the parental cells and drug-resistant counterparts.
\end{abstract}

Correspondence to: Dr Amritha Suresh, Integrated Head and Neck Oncology Research Program, DSRG-5, Mazumdar Shaw Centre for Translational Research, Mazumdar Shaw Medical Foundation, Narayana Health, 258/A Bommasandra Industrial Area, Anekal Taluk, Bangalore, Karnataka 560099, India

E-mail: amritha.suresh@ms-mf.org

Key words: chemotherapy, head and neck cancer, drug resistance, cell lines, cisplatin, docetaxel, 5-fluorouracil, multidrug resistance genes, apoptosis
The Hep-2 TPFR and CAL-27 TPFR cells exhibited a higher resistance index $(R I \geq 2)$ compared with that of the parental cells. Cell cycle analysis revealed a decreased number of TPFR cells in G0/G1 phase $(\mathrm{P}<0.05)$ and a corresponding accumulation of cells in $\mathrm{G} 2 / \mathrm{M}$ phase. A reduced degree of apoptosis in these cells (Hep-2, 33 vs $20 \%, \mathrm{P}=0.003$; and CAL-27, 18 vs $9.7 \%$ ) was complemented by an increased expression of genes involved in drug resistance, including MDR1, MRP2, ERCC1, CTR, survivin and thymidylate synthase. The present study, therefore, established two multi drug-resistant head and neck squamous cell carcinoma cell lines and characterized these cells on a cellular and molecular level. Development of these tools accentuates their requirement in the field of drug discovery and in mechanistic studies elucidating the underlying mechanisms of drug resistance.

\section{Introduction}

Head and neck squamous cell carcinomas (HNSCC) are loco-regionally aggressive tumors, which result in debilitating functional and aesthetic sequelae in patients. Chemotherapeutic management of patients with HNSCC typically involves treatment with taxol (docetaxel), platinum compounds (e.g. cisplatin or carboplatin) and the anti-metabolite 5-fluorouracil (5-FU), either as single agents or in combination. Preclinical and clinical studies indicate a potential synergy between the three drugs $(1,2)$; however, drug resistance accounts for high rates of loco-regional recurrence (3). The process of drug resistance is mediated by modulations in multiple molecular pathways, including drug efflux/metabolism, DNA repair, apoptosis and cell cycle control (4-6). An improved understanding of the cellular and molecular mediators of drug resistance may potentially lead to the identification of candidate genes and pathways, which can be targeted to improve therapeutic efficacy.

In vitro model systems have been ideal for delineating the mechanisms contributing towards the phenomenon of drug resistance and also for identifying novel druggable 
targets. Resistant cell lines developed from ovarian and breast cancer cells have been instrumental in understanding its molecular basis. Copper transporter genes and P-glycoprotein have been implicated to impart resistance to cisplatin and cross-resistance to paclitaxel, respectively (7). The role of melanoma antigen, $\mathrm{G}$ antigen family of genes and ATP-binding cassette $(\mathrm{ABC})$ transporters were identified using resistant cell lines (8-13). High-throughput studies comparing the cisplatin-sensitive/resistant HNSCC cells have indicated the involvement of multiple pathways (14). Activation of survival signaling and apoptotic pathways have been demonstrated to result in the overexpression of rat sarcoma/rapidly accelerated fibrosarcoma/mitogen-activated protein kinase kinase (15) and other genes, including Dickkopf-related protein 1, signal transducer and activator of transcription 3 and Notch $1(16,17)$. Docetaxel resistance in in vitro models has also been correlated with increased expression levels of multidrug resistance (MDR)1/multidrug resistance-associated protein 1 (MRP) and an increase in mitochondrial DNA and reactive oxygen species $(18,19)$. Di-hydropyrimidine (DPD) and thymidylate synthase (TS), which are involved in 5-FU metabolism, have been reported to be important in determining the sensitivity of the head and neck cancer cells to the drug $(20,21)$. Treatment with a combination of drugs has been reported to demonstrate a synergistic effect on the modulation of the cell cycle, angiogenesis and signal transduction, as observed in cells treated with cisplatin and docetaxel (22). Although multiple pathways have been implicated in the process of drug resistance, the underlying mechanisms remain to be elucidated, particularly in the case of resistance to combinatorial therapy.

The present study aimed to facilitate an understanding of resistance to the TPF regimen of drugs. Towards this effort, cell lines resistant to this combination of drugs were established and their resistance index was determined. The resistant cell lines were evaluated for the changes in cell cycle distribution and apoptotic patterns. In addition, the expression profile of the molecular markers involved in resistance to TPF-based drug action was compared between the parental and resistant cells. These markers included drug transporters, such as MDR1, MRP2 and copper transporter (CTR1), as well as survivin, which is involved in cell survival, excision repair cross-complementing rodent repair deficiency, complementation (ERCC1), which is involved in DNA repair, and TS, which is involved in nucleotide synthesis/metabolism.

\section{Materials and methods}

Reagents, cell lines and culture. The chemotherapeutic drugs cisplatin [cis-diammineplatinum (II) dichloride], docetaxel, 5-FU and other reagents, including MTT, propidium iodide (PI) and RNase A, were purchased from Sigma-Aldrich (St. Louis, MO, USA). The reconstitution of the drugs was according to the manufacturer's instructions. Briefly, cisplatin was dissolved in $0.9 \%$ sodium chloride solution, while docetaxel and 5-FU were reconstituted in dimethyl sulfoxide (DMSO; HiMedia India Pvt., Ltd., Mumbai, India). The stock solutions of the drugs were stored in aliquots at $-80^{\circ} \mathrm{C}$. The HNSCC cell lines CAL-27, kindly gifted by Dr Aditi Chatterjee (Institute of Bioinformatics, Bangalore) and Hep-2 (National Centre for Cell Science, Maharashtra,
India) (passage number 28-30), were used in the present study. The cell lines were cultured in Dulbecco's modified Eagle's medium (Gibco-BRL, Invitrogen Life Technologies, Carlsbad, CA, USA), supplemented with $10 \%$ heat-inactivated fetal bovine serum and $1 \mathrm{X}$ penicillin $(100 \mathrm{U} / \mathrm{ml}) /$ streptomycin $(100 \mathrm{mg} / \mathrm{ml})$ (HiMedia India Pvt., Ltd.). The cells were grown as monolayer cultures and maintained in a humidified atmosphere of $5 \% \mathrm{CO}_{2}$ at $37^{\circ} \mathrm{C}$.

Development of drug-resistant cell lines. The methodology for developing the resistant cell lines were based on the methods described previously (23). Briefly, the Hep-2 and CAL-27-resistant sublines were selected based on constant exposure of the parental cells to the combination of docetaxel, cisplatin and 5-FU (TPF) in a stepwise dose incremental strategy. For each cell line, the half maximal inhibitory concentration $\left(\mathrm{IC}_{50}\right)$ of each drug was calculated by MTT or trypan blue assay. The two cell lines were treated with a sequential increase in dosage of the three drugs ranging from $\mathrm{IC}_{6.25}$ (Hep-2: $0.42 \mu \mathrm{M}$ cisplatin, $1.38 \mathrm{nM}$ docetaxel, $10.35 \mu \mathrm{M}$ 5-FU; CAL27: $0.43 \mu \mathrm{M}$ cisplatin, $0.22 \mathrm{nM}$ docetaxel, $0.22 \mu \mathrm{M}$ 5-FU), $\mathrm{IC}_{12.5}$ (Hep-2: $0.84 \mu \mathrm{M}$ cisplatin, $2.75 \mathrm{nM}$ docetaxel, $20.70 \mu \mathrm{M}$ 5-FU; CAL27: $0.86 \mu \mathrm{M}$ cisplatin, $0.44 \mathrm{nM}$ docetaxel, $0.44 \mu \mathrm{M} 5-\mathrm{FU}), \mathrm{IC}_{25}$ (Hep-2: $1.68 \mu \mathrm{M}$ cisplatin, $5.50 \mathrm{nM}$ docetaxel, $41.41 \mu \mathrm{M}$ 5-FU; CAL27: $1.71 \mu \mathrm{M}$ cisplatin, $0.87 \mathrm{nM}$ docetaxel, $0.88 \mu \mathrm{M}$ 5-FU) to $\mathrm{IC}_{50}$. Individual $\mathrm{IC}_{50}$ values are presented in Table I. Cells were incubated for $24 \mathrm{~h}$ with each concentration of the drug. Following each drug treatment, the surviving cells were cultured in drug-free medium for a period of 3-5 days and following the third cycle of drug treatment, the resistant cells were cultured in the presence of drug-containing medium. These cells were used for cytotoxicity assays to assess the $\mathrm{IC}_{50}$-value post-exposure.

Drug sensitivity assay. Briefly, the parental and resistant cells were plated at a concentration of $1 \times 10^{4}$ cells/well in 96-well plates. The cells were incubated overnight in humidified air with $5 \% \mathrm{CO}_{2}$ at $37^{\circ} \mathrm{C}$. The cells were subsequently treated with serial dilutions of drugs or vehicle control for $24 \mathrm{~h}$, followed by further culture in drug-free medium for two days. An MTT assay was performed, according to the manufacturer's instructions. Briefly, $20 \mu \mathrm{l} \mathrm{MTT} \mathrm{(5} \mathrm{mg/ml;} \mathrm{Sigma-Aldrich)}$ was added following the removal of the culture medium and the cells incubated for $4 \mathrm{~h}$ at $37^{\circ} \mathrm{C}$. The formazan crystals were dissolved by adding $100 \mu 1 \mathrm{DMSO}$ per well and the plate was read at $570 \mathrm{~nm}$ against $690 \mathrm{~nm}$, as the reference wavelength, using a microplate reader (Model 680; Bio-Rad Laboratories, Inc., Hercules, CA, USA). Cells without drug were used as the control. The percentage of viable cells was calculated using the formula: Mean optical density (OD) of the experiment / mean OD of the control x100. All assays were performed in triplicate. For the cell viability staining assays, the cells were plated and treated with the different concentrations of the drug in triplicate and the percentage of viable cells was counted following staining with trypan blue (Sigma-Aldrich). The $\mathrm{IC}_{50}$-values in each case were calculated using regression analysis (Microsoft Excel 7; Microsoft Corporation, Redmond, WA, USA) and are expressed as an average of triplicate experiments. The resistance index (RI) was calculated by the ratio of the $\mathrm{IC}_{50}$ of resistant cell lines over the parental cell lines. Chemoresistance was defined as an RI of $\geq 2$. 
Table I. $\mathrm{IC}_{50}$-values for the resistant cell lines.

\begin{tabular}{|c|c|c|c|c|}
\hline Cell line & Drug & $\mathrm{IC}_{50}^{\mathrm{a}}$ & SEM & RI \\
\hline \multicolumn{5}{|l|}{ Parental cells } \\
\hline \multirow[t]{3}{*}{ Hep-2 P } & Cisplatin & 3.35 & 0.13 & \\
\hline & Docetaxel & 11.00 & 2.41 & \\
\hline & $5-\mathrm{FU}$ & 82.81 & 10.84 & \\
\hline \multirow[t]{3}{*}{ CAL-27 P } & Cisplatin & 3.43 & 0.06 & \\
\hline & Docetaxel & 1.56 & 0.55 & \\
\hline & $5-\mathrm{FU}$ & 1.76 & 1.20 & \\
\hline \multicolumn{5}{|l|}{ TPF cell lines } \\
\hline \multirow[t]{3}{*}{ Hep-2 TPFR } & Cisplatin & 16.90 & 0.23 & 5.04 \\
\hline & Docetaxel & 53.57 & 0.51 & 4.87 \\
\hline & $5-\mathrm{FU}$ & 512.55 & 12.39 & 6.19 \\
\hline \multirow[t]{3}{*}{ CAL-27 TPFR } & Cisplatin & 6.75 & 0.15 & 1.97 \\
\hline & Docetaxel & 3.17 & 0.10 & 2.02 \\
\hline & 5-FU & 14.93 & 5.44 & 8.48 \\
\hline
\end{tabular}

${ }^{a} \mathrm{IC}_{50}$ of cisplatin and 5-FU in $\mu \mathrm{M}$ and docetaxel in $\mathrm{nM}$; SEM, standard error of the mean; RI, resistance index; $\mathrm{IC}_{50}$, half maximal inhibitory concentration; 5-FU, 5-fluorouracil; TPF, combination of docetaxel, cisplatin and 5-FU; R, resistant; P, parental.

Cell cycle assay. Resistant and parental cells $\left(1 \times 10^{5}\right)$ were resuspended in $0.3 \mathrm{ml}$ phosphate-buffered saline (PBS; HiMedia India Pvt., Ltd.) and fixed in $0.7 \mathrm{ml}$ cold ethanol (70\%; Merck Millipore, Darmstadt, Germany). The cells were incubated on ice for $1 \mathrm{~h}$, followed by a single wash with ice-cold PBS. The resuspended cell pellet was incubated at $37^{\circ} \mathrm{C}$ for $40 \mathrm{~min}$ in the presence of $5 \mu 110 \mathrm{mg} / \mathrm{ml}$ RNase A (Sigma-Aldrich), $5 \mu 110 \mathrm{mg} / \mathrm{ml}$ PI (Sigma-Aldrich) and $0.05 \%$ Triton X-100 (Sigma-Aldrich). The cells were stored in the dark at $40^{\circ} \mathrm{C}$ until analyzed on a FACSCalibur (BD Biosciences, Franklin Lakes, NJ, USA). The percentage of cells in each cycle was calculated using Cell Quest Pro version 6 (BD Biosciences) software. The experiments on each cell line were performed in triplicate.

Apoptosis assay. An apoptosis assay was performed using annexin V-fluorescein isothiocyanate (FITC; BD Biosciences) and PI (Sigma-Aldrich) staining. The parental and resistant cells from each cell line were treated for $48 \mathrm{~h}$ with the $\mathrm{IC}_{25}$ for all three drug treatments. Following trypsinization, $\sim 1 \times 10^{5}$ cells were resuspended in $100 \mu \mathrm{l}$ binding buffer containing annexin V-FITC $(5 \mu \mathrm{l} ; 20 \mu \mathrm{g} / \mathrm{ml})$ and PI $(10 \mu \mathrm{l}$; $20 \mu \mathrm{g} / \mathrm{ml}$ ) for $15 \mathrm{~min}$ at room temperature in the dark. Following incubation, $400 \mu 1$ annexin binding buffer was added and the percentage of apoptotic cells (cells which were annexin-positive and/or PI-positive) was calculated using a FACSCalibur (BD Biosciences). Untreated cells and cells incubated with PI or annexin V alone were used as controls.

Expression profiling. The mRNA expression levels of the multidrug resistance-associated genes MDR1, MRP2, ERCC1, CTR1, survivin and TS were determined using a Step One polymerase chain reaction machine (Applied Biosystems, Foster City, CA, USA). The total RNA was extracted from $1 \times 10^{6}$ cells using TRIzol reagent (Sigma-Aldrich), according to the manufacturer's instructions. The RNA was treated with DNase (Thermo Fisher Scientific, Waltham, MA, USA) and $\sim 1 \mu \mathrm{g}$ RNA was converted into cDNA using a High Capacity cDNA conversion kit (Applied Biosystems) according to the manufacturer's instructions. The expression of the MDR genes was calculated using specific primer sets (Amnion Biosciences Pvt. Ltd., Bengaluru, India; Table II). PCR conditions were set as follows: Initial denaturation at $95^{\circ} \mathrm{C}$ for $10 \mathrm{~min}$ and $95^{\circ} \mathrm{C}$ for $15 \mathrm{sec}$, followed by 40 cycles at $95^{\circ} \mathrm{C}$ for $15 \mathrm{sec}$ and $60^{\circ} \mathrm{C}$ for $1 \mathrm{~min}$. Melting curve conditions were as follows: $95^{\circ} \mathrm{C}$ for $15 \mathrm{sec}, 60^{\circ} \mathrm{C}$ for $1 \mathrm{~min}$ and $95^{\circ} \mathrm{C}$ for $15 \mathrm{sec}$. Relative quantification was performed using GAPDH as the endogenous control and the parental cells as the calibrator. The relative comparison method $(\Delta \Delta \mathrm{Ct})$ was used for the quantification of mRNA expression for all target genes with untreated parental cells as the calibrator

Statistical analysis. Data are expressed as the mean \pm standard error of the mean. Differences between the parental and resistant cell lines were analyzed for statistical significance using Student's t-test. ${ }^{*} \mathrm{P}<0.05$ was considered to indicate a statistically significant difference between values. Statistical analysis and graphical illustration of datasets was performed using the GraphPad Prism 6.00 statistical software (GraphPad Software, La Jolla, CA).

\section{Results}

Resistance characteristics of the cell lines. The $\mathrm{IC}_{50}$ concentration of each drug for the two cell lines was assessed by exposing them to increasing concentrations of the drug and then evaluating the cell viability. The $\mathrm{IC}_{50}$ values of the parental cells are presented in Table I. The cell lines were subsequently exposed to increasing concentrations $\left(\mathrm{IC}_{6.25}, \mathrm{IC}_{12.5}, \mathrm{IC}_{25}\right.$ and $\mathrm{IC}_{50}$ ) of each drug in combination for developing resistance 
Table II. List of primers used for expression profiling.

\begin{tabular}{llc}
\hline Gene & \multicolumn{1}{c}{ Primer sequence } & Amplicon (bp) \\
\hline MDR1 & $\begin{array}{l}\text { Forward: 5'TGACAGCTACAGCACGGAAG3' } \\
\text { Reverse: 3'TCTTCACCTCCAGGCTCAGT5' }\end{array}$ & 134 \\
MRP2 & Forward: 5'TACCAATCCAAGCCTCTCC3' \\
& Reverse: 3'AGAATAGGGACAGGAACCAG5' & 104 \\
CTR1 & Forward: 5'AGGACTCAAGATAGCCCGAGAGA3' & 78 \\
& Reverse: 3'TGGTCCTGGGACAGGCATGG5' & 159 \\
Survivin & Forward: 5'GAGGCTGGCTTCATCCACTG3' \\
ERCC1 & Reverse:5'GCACTTTCTTCGCAGTTCCTC3' & 60 \\
TS & Forward: 5'GGCGACGTAATTCCCGACTA3' & 63 \\
GAPDH & Reverse: 3'AGTTCTTCCCCAGGCTCTGC5' & 63 \\
& Forward: 5'GGCCTCGGTGTGCCTTT3' & 105 \\
\hline
\end{tabular}

(Fig. 1A-F). The drug-free period between each concentration was decided based on the recovery period required for each cell line-drug combination. The cells were continuously maintained in drug-containing medium prior to performing the assays. The resistant cell lines Hep-2 TPF resistant (TPFR) and CAL-27 TPFR were initially assessed for their resistance characteristics by cell viability assays.

The Hep-2 TPFR cells demonstrated an increase in the $\mathrm{IC}_{50}$ compared with that of the parental cell line (RI=2-9), with the exception of the resistance to cisplatin in CAL-27 TPFR cells (RI=1.97; Fig. 1A-F; Table I). These results indicated the development of a drug-resistant phenotype in these cell lines.

Cell cycle and apoptosis analysis. Analysis of the cell cycle pattern using PI staining demonstrated a decreased accumulation of cells in G0/G1 phase in the resistant cell lines (Hep-2 TPFR, 74 vs 66\%, $\mathrm{P}=0.017$; CAL-27 TPFR, 64 vs 53\%, $\mathrm{P}=0.002$; Fig. 2A-C). At basal levels, this decrease in the G0/G1 phase population was accompanied by a corresponding increase in the accumulation of cells in G2/M phase (Hep-2 TPFR, 12 vs $20 \%, \mathrm{P}=0.001$; CAL-27 TPFR, 18 vs $28 \%$; $\mathrm{P}=0.02$ ).

Annexin $\mathrm{V}$ assays using the resistant sublines revealed a decreased apoptotic rate of the TPFR cell lines following incubation with the drugs. Hep-2 TPFR cells demonstrated a significant reduction in the percentage of apoptotic cells (TPFR, 20\%; parental, 33\%; $\mathrm{P}=0.003$ ). The apoptotic rate of CAL-27 TPFR cells was also decreased; however, differences were not significant (TPFR, 9.7\%; parental, $18 \%$; $\mathrm{P}=0.2$; Fig. 3A and B).

Expression of MDR genes. The cell lines were profiled for the expression levels of the MDR genes, including MDR1, MRP2 (ABCC2), survivin, ERCC1, CTR1 and TS, in order to determine whether they were involved in the resistance of the three drugs under investigation. Quantitative profiling of the transcript levels indicated a concomitant increase in the expression levels of all these markers in the TPF-treated cell lines (Hep-2
TPFR: Median increase, 3.6-fold and range, 2-5.8; CAL-27 TPFR: Median increase, 3-fold and range, 1.7-8.2; $\mathrm{P}<0.05$; Fig. 3C). The upregulation of survivin, CTR1, TS and ERCC1 was significant in the Hep-2 TPFR cells as compared with levels in the parental cells $(\mathrm{P}<0.005)$, with survivin and CTR1 demonstrating a highly significant upregulation $(\mathrm{P}<0.0005)$. The CAL-27 TPFR cell line demonstrated a significant upregulation of CTR1, ERCC1 and TS (Ps0.005).

\section{Discussion}

Drug-resistant cell lines are essential in-vitro model systems, as they can facilitate an understanding of the underlying mechanisms of clinical anti-cancer drug resistance. Cell line models with acquired resistance to a broad range of anti-cancer drugs have been generated and investigated in various types of cancer, including HNSCC $(14,22,24-30)$. The present study generated two HNSCC cell lines resistant to a combination of three drugs, docetaxel, cisplatin and 5-FU, routinely utilized in the clinical treatment of patients with HNSCC. Sequential treatment of the two cell lines (Hep-2 and CAL-27) with an intermittent drug-free period led to the successful development of the drug-resistant phenotype characterized by $\mathrm{RI} \geq 2$.

The three chemotherapeutic agents used in the present study vary in their mechanism of action. Cisplatin is an alkylating agent, which binds to DNA and forms intrastrand crosslinks and DNA adducts, which ultimately lead to apoptosis (31). Docetaxel is a semisynthetic taxane, which inhibits microtubule depolymerization leading to mitotic catastrophe and cell death (32). 5-FU is an anti-metabolite, which exerts its anti-neoplastic activity by inhibiting thymidylate synthase and mis-incorporation of fluoronucleotides into RNA and DNA (33). Preclinical and clinical studies have previously demonstrated that the combination of these drugs results in a synergistic increase in anti-tumor activity. The combination of TPF has been demonstrated to increase the survival rate in patients with locally advanced HNSCC (34). However, 30-40\% 
A

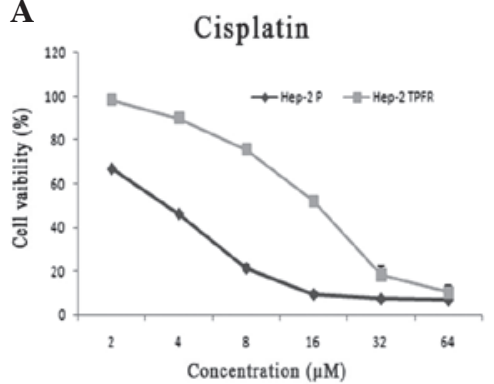

D

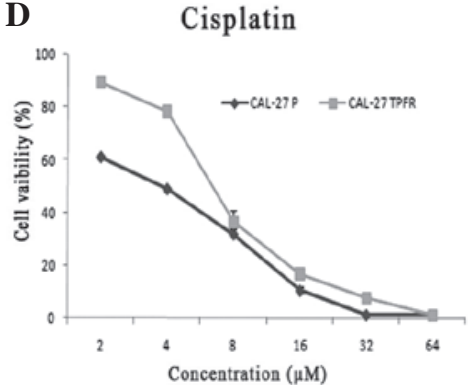

B

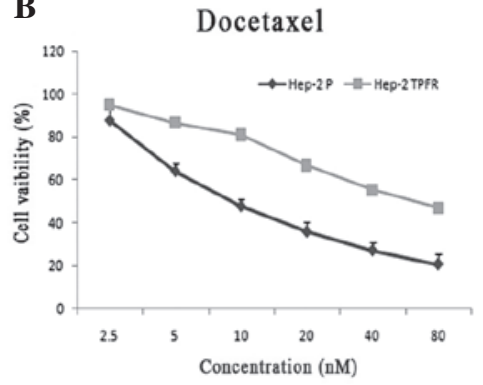

$\mathbf{E}$

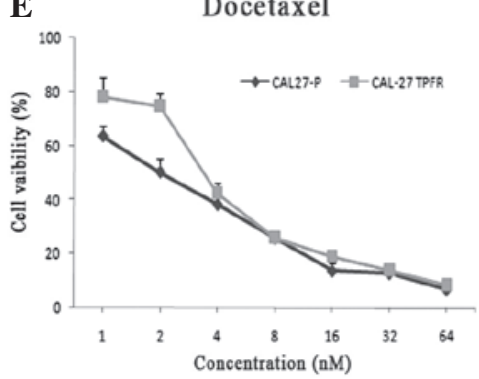

C

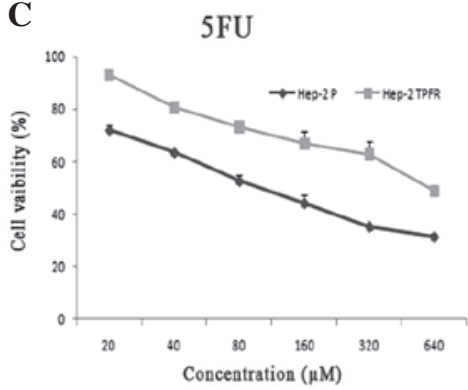

$\mathbf{F}$

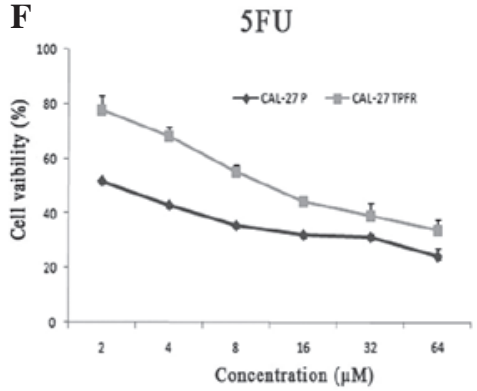

Figure 1. Tumor cells treated with TPF demonstrated an increased resistance to the three drugs. $\mathrm{IC}_{50}$ values of the TPF-resistant cells generated from (A-C) Hep-2 and (D-F) CAL-27 cells following sequential treatment with the combination of the drugs, were assessed by MTT assays. The viability of these cells was evaluated against treatment with (A and D) cisplatin, (B and E) docetaxel and (C and F) 5-FU. The resistant cell lines, Hep-2 TPFR and CAL-27 TPFR, demonstrated a significant increase in the $\mathrm{IC}_{50}$ values as analyzed by GraphPad Prism software. Experiments were performed in triplicate $(\mathrm{P}<0.05$, as compared with the parental cells). 5-FU, 5-fluorouracil; TPFR, combination of docetaxel, cisplatin and 5-FU; IC 5 , half maximal inhibitory concentration; R, resistant; P, parental.

of the patients treated with the TPF regimen do not respond to these therapies (35-37). In HNSCC, cisplatin in combination with docetaxel demonstrated a response rate of $\sim 88 \%$ (38), whereas in combination with paclitaxel it demonstrated a response rate of $40 \%$ in recurrent cancer (39). This property of multi-drug resistance is primarily responsible for the low response rates in this subset of patients. Cell lines resistant to all three drugs may serve as an important model to assess the underlying mechanisms.

The concept underlying combination therapy is the synergistic benefit due to multiple drug action. However, the different mechanisms involved may also be responsible for inducing drug resistance. Cell cycle-mediated drug resistance to combination chemotherapy is currently being investigated. One of the primary effects of cytotoxic drug action is a reduction in the G0/G1 phase population and an arrest in G2/M phase of the cell cycle, of which the latter is known to guide the damaged cells to the apoptotic pathway. Previous studies have demonstrated that $\mathrm{G} 2 / \mathrm{M}$ phase arrest increases the cytotoxicity of agents in gastric cancer, prostate tumor and neuronal cells in vitro (40-42). In contrast, a prolonged arrest in this phase of the cell cycle is also known to be one of the mechanisms used to escape apoptosis by enabling repair of the damaged DNA and thereby rendering themselves resistant to the drugs. Abrogation of this G2/M checkpoint is known to render cells sensitive to apoptosis (43), to agents, including mitomycin C, in human colon carcinoma cells (44) and to radiation in breast cancer cells (45). The present study indicated a significant $\mathrm{G} 2 / \mathrm{M}$ phase arrest in each of the resistant cell lines. This arrest may be due to the combined effect of cisplatin, which induces arrest in the early G2/M phase, and docetaxel, which induces mitotic arrest, with this fraction of cells contributing to the resistance phenotype. An arrest in G2 phase by activation of cell cycle checkpoints was also reported to be the mechanism adopted by cancer stem-like cells to evade apoptosis (46); the relevance of this concept in these resistant cells remains to be elucidated.

As reported by other studies, the accumulation of cells in $\mathrm{G} 2 / \mathrm{M}$ phase observed in the present study is also accompanied by a corresponding upregulation of the survivin gene, a member of the inhibitor of apoptosis family, known to inhibit apoptosis and thereby induce resistance in several types of cancer $(47,48)$. The overexpression of this gene in each of the resistant cell lines suggested its role in the induction of drug resistance in the HNSCC cell lines investigated. The ABC transporters, MDR1 and MRP2, were the other class of genes upregulated in the resistant cell lines generated in the present study. In vitro assessment indicated their role in resistance to cisplatin and other cytotoxic drugs $(29,30)$. Previous studies correlating their expression levels to patient outcome suggested the downregulation of these markers to be predictive of disease-free and overall survival $(49,50)$.

ERCC1 and CTR1 are molecules associated with cisplatin resistance in several solid types of tumor $(51,52)$. An increase in the expression of the CTR1 gene, the copper influx transporter, increases the intake of cisplatin in the cells $(53,54)$, thereby increasing sensitivity. However, a study using ovarian cancer cells demonstrated that an increase in CTR1 was not accompanied by an increase in susceptibility to the drug, possibly due to a lack of access to its targets (54). The present study demonstrated the overexpression of ERCC1 and a marginal upregulation of CTR1 in the TPFR cells, suggesting that they have a role in the resistance of the cells to TPF. Previous studies on HNSCC have also revealed an increased expression 
A

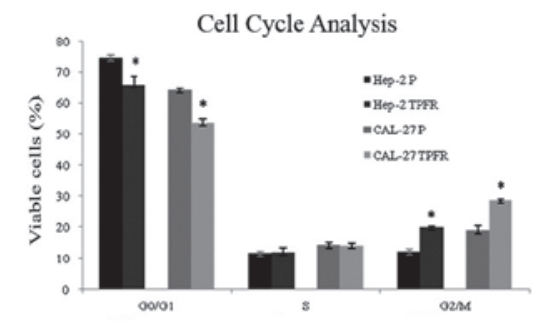

$\mathbf{C}$
B

\begin{tabular}{llllllll} 
& \multicolumn{6}{c}{ Distribution of cells in the cell cycle } \\
& GO/G1 & SEM & S & SEM & G2M & SEM \\
\hline Hep-2P & 74.5225 & 0.9423 & 11.75 & 0.523283 & 12.2675 & 0.614 \\
Hep-2 TPFR & $66^{*}$ & 2.6517 & 9.1 & 1.55917 & $20.09^{*}$ & 0.198 \\
& & & & & & \\
CAL.27P & 64.21 & 0.5812 & 14.19 & 0.986378 & 18.78 & 1.707 \\
CAL.27 TPFR & $53.8^{*}$ & 1.1031 & 21.23 & 0.813173 & $28.82^{*}$ & 0.103
\end{tabular}

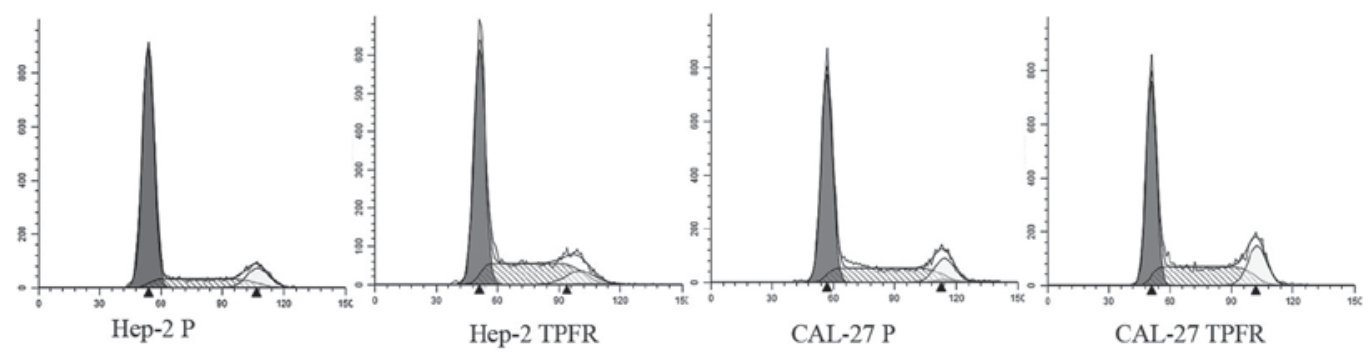

Figure 2. Resistant cell lines exhibit deregulation of the cell cycle. The parental and resistant cell lines were assessed for changes in the cell cycle. At basal levels, the two resistant cell lines demonstrated a deregulation following sequential treatment with TPF. (A) The Hep-2 and CAL-27 TPFR cell lines exhibited a significant reduction in the number of cells in $\mathrm{G} 0 / \mathrm{G} 1$, and a $\mathrm{G} 2 / \mathrm{M}$ phase arrest ( $\mathrm{P}<0.05$, as compared with the parental cells). (B) The distribution of the parental and the resistant cells in the different phases of the cell cycle $\left({ }^{\#} \mathrm{P}<0.05 ;{ }^{*} \mathrm{P}<0.005\right.$, as compared with the parental cells). (C) Representative histograms of cell cycle distributions of the parental and the resistant cell lines. TPF, combination of docetaxel, cisplatin and 5-fluorouracil; TPFR, TPF resistant; P, parental.

A

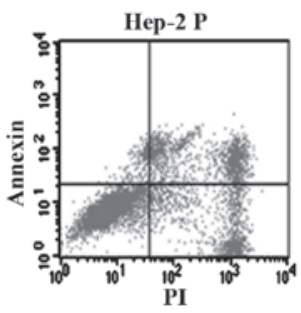

B
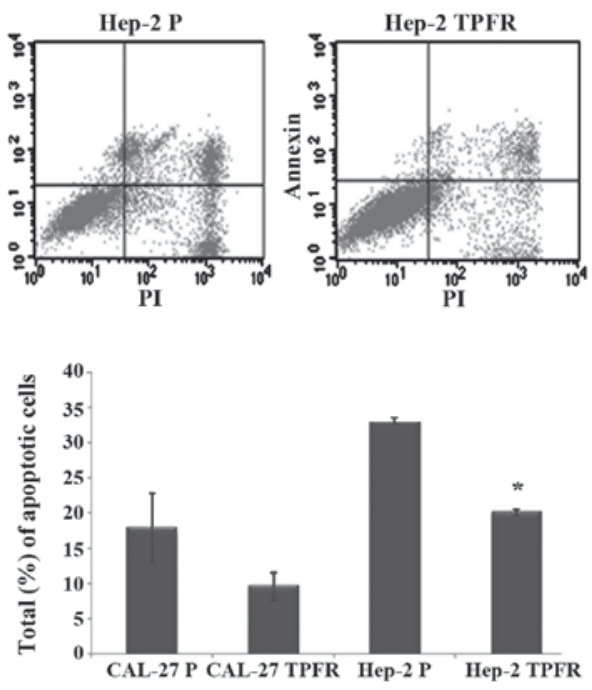
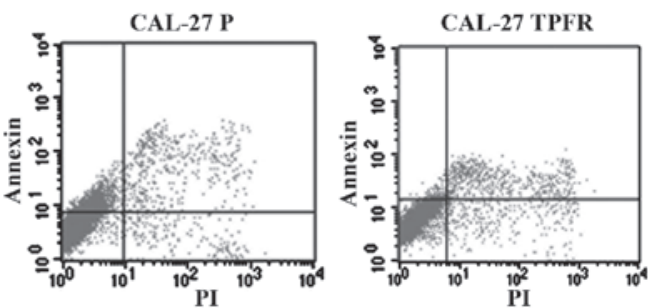

C

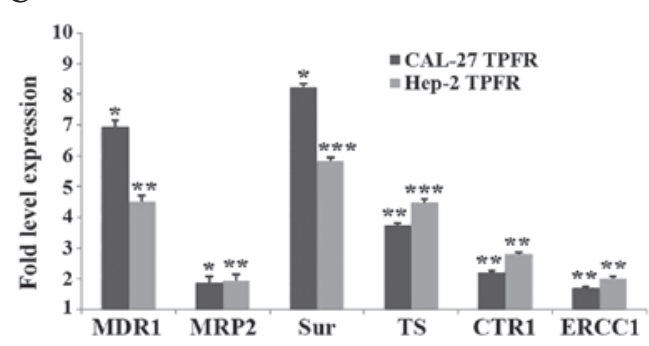

Figure 3. Apoptotic rate and expression profiles of resistance-associated genes. (A and B) The resistant cell lines demonstrated decreased level of apoptosis. The TPFR cells were analyzed by annexin-V staining to assess the apoptotic pattern. (A) Representative dot plots indicated the total apoptotic patterns for the parental Hep-2 and CAL-27 cells and their resistant counterparts. (B) The resistant cells revealed a decreased population (Hep-2 TPFR, 33 to 20\%, P=0.003; CAL-27 TPFR, 18 to 9.7\%) in the apoptotic quadrants (PI-positive, annexin V-positive and PI + annexin V positive). Values are expressed as the mean \pm standard error of the mean of three independent experiments. (C) The expression of resistance genes, MDR1, MRP2, Sur, Ts, CTR1 and ERCC1, were increased in the TPFR cell lines. All the genes were upregulated in the two TPFR cell lines compared with levels in the parental untreated cells. " $\mathrm{P}<0.05$; ${ }^{* *} \mathrm{P}<0.005$; ${ }^{* * *} \mathrm{P}<0.0005$, as compared with the parental untreated cells. TPF, combination of docetaxel, cisplatin and 5-fluorouracil; TPFR, TPF resistant; P, parental; PI, propidium iodide; MDR, multidrug resistance; Sur, survivin; CTR, copper transporter; ERCC, excision repair cross-complementing rodent repair deficiency, complementation; TS, thymidylate synthase.

of CTR1 in resistant patients, indicating that this may be an effect of exposure to the drug treatment. Induction of TS is one of the mechanisms underlying 5-FU resistance $(55,56)$ and an increased expression of this gene was also observed in the resistant cell lines established in the present study. In the present study, expression profiling of these multi-drug resistance genes indicated a synergistic action in the TPF-resistant cell lines, whereby all these markers were upregulated.

Multimodal chemotherapy has been conceived with the concept of combining chemotherapeutic drugs to increase the cytotoxic effect on the cells. With the increase in the understanding of individual drug action, effects on the cell cycle and the processes of acquired drug resistance, it is clear that there is a requirement for refining the concept to determine improved results. An in vitro study on the effects of cisplatin, docetaxel and 5-FU provided evidence towards the inverse association observed between resistance to cisplatin and docetaxel in cell lines (57). It was also suggested that platinum- and taxol-resistant cell lines exhibited cross resistance with the molecular background being of prime importance. The overexpression 
of the MRP2 gene is known to mediate docetaxel resistance in cisplatin-resistant cell lines (7). The consistent upregulation of MDR1/MRP2 in the cell lines suggested their role in multidrug resistance to the majority of chemotherapeutic drugs. Sequential administration of the drugs, which complements the cellular and molecular effects of various drugs is now being considered an option. An in vitro study indicated that docetaxel treatment is known to downregulate the expression levels of TS and DPD, which in turn render the cells sensitive to 5-FU (58). The sequential treatment of cells with docetaxel, followed by $5-\mathrm{FU}$, therefore increased the cytotoxicity compared with that of the individual or combined treatments. Further investigations into the molecular and cell cycle effects of these drugs may enable an improved insight into the optimal methods of performing combination chemotherapy.

The present study described the establishment of triple drug-resistant cell lines and also provided valuable insight into the mechanism of resistance in a multidrug-resistant phenotype. Further evaluations of these resistant sublines may provide valuable inputs into the cellular and molecular methods adopted for acquiring drug resistance. The global differences in the gene expression profiles of these cells and the possible role of stem cells in the process of acquiring drug resistance is another area of interest currently under investigation.

\section{Acknowledgements}

The authors would like to thank Dr Aditi Chatterjee (Institute of Bioinformatics, Bangalore) for her kind gift of the CAL-27 cells. The present study was supported by the Department of Biotechnology, India (no. BT/PR15027/GBD/27/286/2010) and the fellowship for SVG from the Indian Council of Medical Research (ICMR) is also acknowledged.

\section{References}

1. Kogashiwa Y, Sakurai H, Kimura T and Kohno N: Docetaxe suppresses invasiveness of head and neck cancer cells in vitro. Cancer Sci 101: 1382-1386, 2010.

2. Pignon JP, Syz N, Posner M, et al: Adjusting for patient selection suggests the addition of docetaxel to 5-fluorouracil-cisplatin induction therapy may offer survival benefit in squamous cell cancer of the head and neck. Anticancer Drugs 15: 331-340, 2004.

3. Salama JK, Seiwert TY and Vokes EE: Chemoradiotherapy for locally advanced head and neck cancer. J Clin Oncol 25: 4118-4126, 2007.

4. Posner MR, Hershock DM, Blajman CR, et al: Cisplatin and fluorouracil alone or with docetaxel in head and neck cancer. N Engl J Med 357: 1705-1715, 2007.

5. Bourhis J, Le Maître A, Baujat B, Audry H and Pignon JP: Individual patients' data meta-analyses in head and neck cancer. Curr Opin Oncol 19: 188-194, 2007.

6. Brockstein B, Haraf DJ, Rademaker AW, et al: Patterns of failure, prognostic factors and survival in loco-regionally advanced head and neck cancer treated with concomitant chemoradiotherapy: a 9-year, 337-patient, multi-institutional experience. Ann Oncol 15: 1179-1186, 2004.

7. Stordal B, Hamon M, McEneaney V, et al: Resistance to paclitaxel in a cisplatin-resistant ovarian cancer cell line is mediated by P-glycoprotein. PLoS One 7: e40717, 2012.

8. Duan Z, Ames RY, Ryan M, Hornicek FJ, Mankin H and Seiden MV: CDDO-Me, a synthetic triterpenoid, inhibits expression of IL- 6 and Stat 3 phosphorylation in multi-drug resistant ovarian cancer cells. Cancer Chemother Pharmacol 63: 681-689, 2009

9. Wahl H, Tan L, Griffith K, Choi M and Liu JR: Curcumin enhances Apo2L/TRAIL-induced apoptosis in chemoresistant ovarian cancer cells. Gynecol Oncol 105: 104-112, 2007.
10. Duan Z, Duan Y, Lamendola DE, et al: Overexpression of MAGE/GAGE genes in paclitaxel/doxorubicin-resistant human cancer cell lines. Clin Cancer Res 9: 2778-2785, 2003.

11. Husain A, He G, Venkatraman ES and Spriggs DR: BRCA1 up-regulation is associated with repair-mediated resistance to cisdiamminedichloroplatinum(II). Cancer Res 58: 1120-1123, 1998.

12. Hill BT, Whelan RD, Shellard SA, McClean S and Hosking LK: Differential cytotoxic effects of docetaxel in a range of mammalian tumor cell lines and certain drug resistant sublines in vitro. Invest New Drugs 12: 169-182, 1994.

13. Plumb JA, Luo W and Kerr DJ: Effect of polyunsaturated fatty acids on the drug sensitivity of human tumour cell lines resistant to either cisplatin or doxorubicin. Br J Cancer 67: 728-733, 1993.

14. Yamano Y, Uzawa K, Saito K, et al: Identification of cisplatin-resistance related genes in head and neck squamous cell carcinoma. Int J Cancer 126: 437-449, 2010.

15. Aoki K, Ogawa T, Ito Y and Nakashima S: Cisplatin activates survival signals in UM-SCC-23 squamous cell carcinoma and these signal pathways are amplified in cisplatin-resistant squamous cell carcinoma. Oncol Rep 11: 375-379, 2004

16. Gosepath EM, Eckstein N, Hamacher A, et al: Acquired cisplatin resistance in the head-neck cancer cell line Cal27 is associated with decreased DKK1 expression and can partially be reversed by overexpression of DKK1. Int J Cancer 123: 2013-2019, 2008.

17. Gu F, Ma Y, Zhang Z, et al: Expression of Stat 3 and Notch1 is associated with cisplatin resistance in head and neck squamous cell carcinoma. Oncol Rep 23: 671-676, 2010.

18. Li L, Jiang AC, Dong P, Wan Y and Yu ZW: The characteristics of Hep-2 cell with multiple drug resistance induced by Taxol. Otolaryngol Head Neck Surg 137: 659-664, 2007.

19. Mizumachi T, Suzuki S, Naito A, et al: Increased mitochondrial DNA induces acquired docetaxel resistance in head and neck cancer cells. Oncogene 27: 831-838, 2008.

20. Yasumatsu R, Nakashima T, Uryu H, et al: The role of dihydropyrimidine dehydrogenase expression in resistance to 5-fluorouracil in head and neck squamous cell carcinoma cells. Oral Oncol 45: 141-147, 2009.

21. Beck A, Etienne MC, Chéradame S, et al: A role for dihydropyrimidine dehydrogenase and thymidylate synthase in tumour sensitivity to fluorouracil. Eur J Cancer 30A: 1517-1522, 1994.

22. Yoo GH, Lin HS, Iskander AJ, et al: Docetaxel associated pathways in cisplatin resistant head and neck squamous cell carcinoma: a pilot study. Laryngoscope 115: 1938-1946, 2005.

23. Coley HM: Development of drug-resistant models. Methods Mol Med 88: 267-273, 2004.

24. Murakami H, Ito S, Tanaka H, Kondo E, Kodera Y and Nakanishi H: Establishment of new intraperitoneal paclitaxel-resistant gastric cancer cell lines and comprehensive gene expression analysis. Anticancer Res 33: 4299-4307, 2013.

25. Rao GH, Liu HM, Li BW, et al: Establishment of a human colorectal cancer cell line P6C with stem cell properties and resistance to chemotherapeutic drugs. Acta Pharmacol Sin 34: 793-804, 2013.

26. Loh YN, Hedditch EL, Baker LA, Jary E, Ward RL and Ford CE: The Wnt signalling pathway is upregulated in an in vitro model of acquired tamoxifen resistant breast cancer. BMC Cancer 13: 174,2013

27. Takahashi K, Tanaka M, Inagaki A, et al: Establishment of a 5-fluorouracil-resistant triple-negative breast cancer cell line. Int J Oncol 43: 1985-1991, 2013.

28. Maseki S, Ijichi K, Tanaka H, et al: Acquisition of EMT phenotype in the gefitinib-resistant cells of a head and neck squamous cell carcinoma cell line through Akt/GSK-3 $\beta /$ snail signalling pathway. Br J Cancer 106: 1196-1204, 2012.

29. Negoro K, Yamano Y, Fushimi K, et al: Establishment and characterization of a cisplatin-resistant cell line, KB-R, derived from oral carcinoma cell line, KB. Int J Oncol 30: 1325-1332, 2007.

30. Nakamura M, Nakatani K, Uzawa K, et al: Establishment and characterization of a cisplatin-resistant oral squamous cell carcinoma cell line, H-1R. Oncol Rep 14: 1281-1286, 2005.

31. Pinto AL and Lippard SJ: Binding of the antitumor drug cisdiamminedichloroplatinum(II) (cisplatin) to DNA. Biochim Biophys Acta 780: 167-180, 1985.

32. Owellen RJ, Hartke CA, Dickerson RM and Hains FO: Inhibition of tubulin-microtubule polymerization by drugs of the Vinca alkaloid class. Cancer Res 36: 1499-1502, 1976.

33. Longley DB, Harkin DP and Johnston PG: 5-fluorouracil: mechanisms of action and clinical strategies. Nat Rev Cancer 3: 330-338, 2003. 
34. Loehrer PJ, Sr., Einhorn LH, Williams SD, Hui SL, Estes NC and Pennington K: Cisplatin plus 5-FU for the treatment of adenocarcinoma of the colon. Cancer Treat Rep 69: 1359-1363, 1985.

35. Qin H, Luo J, Zhu YP, Xie HL, Yang WQ and Lei WB: Combination of taxanes, cisplatin and fluorouracil as induction chemotherapy for locally advanced head and neck cancer: a meta-analysis. PLoS One 7: e51526, 2012.

36. Hitt R, Paz-Ares L, Brandariz A, et al: Induction chemotherapy with paclitaxel, cisplatin and 5-fluorouracil for squamous cell carcinoma of the head and neck: long-term results of a phase II trial. Ann Oncol 13: 1665-1673, 2002.

37. Hussain M, Salwen W, Kucuk O and Ensley J: Paclitaxel, cisplatin, and 5-fluorouracil in patients with advanced or recurrent squamous cell carcinoma of the head and neck: a preliminary report. Semin Oncol 24: S19-43-S19-45, 1997.

38. Choi YJ, Chung J, Shin HJ, et al: Induction chemotherapy of docetaxel and Cisplatin for the elderly patients with squamous cell carcinoma of the head and neck. Cancer Res Treat 39: 1-5, 2007.

39. Adamo V, Ferraro G, Pergolizzi S, et al: Paclitaxel and cisplatin in patients with recurrent and metastatic head and neck squamous cell carcinoma. Oral Oncol 40: 525-531, 2004.

40. Liu YL, Zhang GQ, Yang Y, Zhang CY, Fu RX and Yang YM: Genistein induces $\mathrm{G} 2 / \mathrm{M}$ arrest in gastric cancer cells by increasing the tumor suppressor PTEN expression. Nutr Cancer 65: 1034-1041, 2013.

41. Ismail IA, Kang KS, Lee HA, Kim JW and Sohn YK: Genistein-induced neuronal apoptosis and G2/M cell cycle arrest is associated with MDC1 up-regulation and PLK1 down-regulation. Eur J Pharmacol 575: 12-20, 2007.

42. Nawab A, Thakur VS, Yunus M, Ali Mahdi A and Gupta S: Selective cell cycle arrest and induction of apoptosis in human prostate cancer cells by a polyphenol-rich extract of Solanum nigrum. Int J Mol Med 29: 277-284, 2012.

43. Wang WZ, Cheng J, Luo J and Zhuang SM: Abrogation of G2/M arrest sensitizes curcumin-resistant hepatoma cells to apoptosis. FEBS Lett 582: 2689-2695, 2008.

44. Wang Q, Fan S, Eastman A, Worland PJ, Sausville EA and O'Connor PM: UCN-01: a potent abrogator of G2 checkpoint function in cancer cells with disrupted p53. J Natl Cancer Inst 88: 956-965, 1996.

45. Sun XC, Cheng HY, Deng YX, Shao RG and Ma J: Tetrandrine: a potent abrogator of $\mathrm{G} 2$ checkpoint function in tumor cells and its mechanism. Biomed Environ Sci 20: 495-501, 2007.

46. Chappell J and Dalton S: Altered cell cycle regulation helps stem-like carcinoma cells resist apoptosis. BMC Biol 8: 63, 2010.
47. Pratt MA, Niu MY and Renart LI: Regulation of survivin by retinoic acid and its role in paclitaxel-mediated cytotoxicity in MCF-7 breast cancer cells. Apoptosis 11: 589-605, 2006.

48. Nestal de Moraes G, Silva KL, Vasconcelos FC and Maia RC: Survivin overexpression correlates with an apoptosis-resistant phenotype in chronic myeloid leukemia cells. Oncol Rep 25: 1613-1619, 2011.

49. Ohishi Y, Oda Y, Uchiumi T, et al: ATP-binding cassette superfamily transporter gene expression in human primary ovarian carcinoma. Clin Cancer Res 8: 3767-3775, 2002.

50. Lee J, Jiffar T and Kupferman ME: A novel role for BDNF-TrkB in the regulation of chemotherapy resistance in head and neck squamous cell carcinoma. PLoS One 7: e30246, 2012.

51. Köberle B, Ditz C, Kausch I, Wollenberg B, Ferris RL and Albers AE: Metastases of squamous cell carcinoma of the head and neck show increased levels of nucleotide excision repair protein XPF in vivo that correlate with increased chemoresistance ex vivo. Int J Oncol 36: 1277-1284, 2010.

52. Hayes M, Lan C, Yan J, et al: ERCC1 expression and outcomes in head and neck cancer treated with concurrent cisplatin and radiation. Anticancer Res 31: 4135-4139, 2011.

53. Song IS, Savaraj N, Siddik ZH, et al: Role of human copper transporter Ctrl in the transport of platinum-based antitumor agents in cisplatin-sensitive and cisplatin-resistant cells. Mol Cancer Ther 3: 1543-1549, 2004

54. Holzer AK, Samimi G, Katano K, et al: The copper influx transporter human copper transport protein 1 regulates the uptake of cisplatin in human ovarian carcinoma cells. Mol Pharmacol 66: 817-823, 2004.

55. Peters GJ, Backus HH, Freemantle S, et al: Induction of thymidylate synthase as a 5-fluorouracil resistance mechanism. Biochim Biophys Acta 1587: 194-205, 2002.

56. Wong NA, Brett L, Stewart M, et al: Nuclear thymidylate synthase expression, p53 expression and 5-FU response in colorectal carcinoma. Br J Cancer 85: 1937-1943, 2001.

57. Saiki Y, Ogawa T, Shiga K, Sunamura M, Kobayashi T and Horii A: A Human Head and Neck Squamous Cell Carcinoma Cell Line with Acquired cis-Diamminedichloroplatinum-Resistance Shows Remarkable Upregulation of BRCA1 and Hypersensitivity to Taxane. Int J Otolaryngol 2011: 521852, 2011

58. Tamatani T, Ferdous T, Takamaru N, et al: Antitumor efficacy of sequential treatment with docetaxel and 5-fluorouracil against human oral cancer cells. Int J Oncol 41: 1148-1156, 2012. 